Çukurova Üniversitesi Mühendislik Mimarlık Fakültesi Dergisi, 32(4), ss. 87-98, Aralık 2017

Çukurova University Journal of the Faculty of Engineering and Architecture, 32(4), pp. 87-98, December 2017

\title{
Farklı Yıkamaların Denim Kumaş Performansı Üzerindeki Etkilerinin Araştırılması
}

\author{
Ramazan Tuğrul OĞULATA ${ }^{* 1}$, Ahmet NERGís ${ }^{1}$ \\ ${ }^{1}$ Çukurova Üniversitesi, Mühendislik Mimarlık Fakültesi, Tekstil Mühendisliği Bölümü, Adana
}

Geliş tarihi: 29.06.2017 Kabul tarihi: 19.12.2017

\section{$\ddot{\mathbf{O} z}$}

Denim kumaş ürünleri için önemli işlemlerden biri yıkama operasyonudur. Yıkama işlemi, dikilmiş denim giysinin, özel yıkama makinelerinde belirli reçete ve tekniklere göre yıkanarak üzerinde bulunan haşılların sökülmesi, değişik renk ve tuşe kazandırılması işlemidir. Yapılan bu çalışmada 6 farklı denim kumaşa, rins, enzim, taş, ağartma ve ev yıkaması yapılmıştır. Yıkamaların kumaşlar üzerindeki etkisini incelemek amacıyla, tekstil kumaşlarının performans tayininde kullanılan yırtılma mukavemeti, kopma mukavemeti, elastikiyet ve kalıcı uzama test metotları uygulanarak elde edilen sonuçlar istatistiksel metotlarla analiz edilmiştir. Deneysel çalışma sonuçlarının değerlendirilmesi ile yıkamanın kopma mukavemeti, yırtılma mukavemeti ve kalıcı uzama üzerinde etkili olduğu, elastikiyet üzerinde ise çok büyük bir etkisinin olmadığı tespit edilmiştir.

Anahtar Kelimeler: Denim, Y1kama, Mukavemeti, Elastikiyet, Kalıcı uzama

\section{Investigation of Effects of Different Washings on Performance for Denim Fabrics}

\begin{abstract}
One of the important processes for denim fabric products is washing operation. Sewn denim wear is washed in special washing machines according to certain prescriptions and techniques, removing the sizes on it, bringing in different colors and touches. In this study 6 different denim fabrics, rins, enzymes, stones, bleaching, house washing were done. In order to investigate the effect of the washings on the fabrics, the results obtained by applying the tear strength, tensile strength, stretch and growth test methods used in the performance evaluation of textile fabrics were analyzed by statistical methods. By evaluating the experimental study results; It has been found that the washing is effective on tear, tensile strength and growth, but not on stretch test.
\end{abstract}

Keywords: Denim, Washing, Strength, Stretch, Growth

"Sorumlu yazar (Corresponding author): Ramazan Tuğrul OĞULATA, ogulata@cu.edu.tr 


\section{GíRiş}

Ortaya çıktığı 19. yüzyıldandan beri devamlı gelişme kaydeden ve moda tasarımında lider akımlardan olan denim kumaşlar, şu anda modanın vazgeçilmez bir parçasıdır. Ünlü moda markaları, değişik ve şaşırtıcı bir koleksiyon yapmak istediklerinde denim kumaşı tercih etmektedirler. Bunun asıl nedeni, genç kitlelerin denim ürünlere olan talebinin artırılması ve bu sayede, değişen yaşam tarzlarının denim ürünlere uygulanarak yeni moda eğilimlerinin oluşturulmasıdır. Yeni moda akımları, müşterilerin denim ürünlere daha fazla yönelimini sağlamakta ve üretici firmaların yıllık cirolarında önemli ölçüde artışlar sağlamaktadır [1].

Hızla gelişen tekstil sektöründe kalite ve üretim hızı önemli bir yere sahiptir. Günümüz teknolojisinde üretim hızı her geçen gün artmakta ve bu artış alıcı açısından çeşitlilikler doğurmaktadır. Artan üretim miktarı, insanları en kaliteli, en ucuz, en farklı, en yeni ürünü alma konusunda seçiciliğe itmektedir. Dolayısıyla bu konuda işletmelere de çok fazla iş düşmektedir. Günümüzde denim kumaşın birçok çeşidi vardır. 19. yy başlarında daha çok open-end ipliği denim imalatı için kullanılırken zamanla daha yumuşak bir denim kalitesi sağlamak amacıyla çözgü ve atkıda karde ring ipliği bunun yerini almıştır. Denim kumaş için kullanılan hammaddelerin de değişiklik göstermesi ile çeşitli özelliklerde denim kumaş üretilebilmektedir. Bunların yanı sıra denim kumaş ağırlıkları değiştirilerek de farklı denim kumaşları elde etmek mümkündür. Ayrıca kumaşın doku yapısı değiştirilerek, değişik bir denim kumaş meydana getirilebilmektedir [2].

Denim kumaş ürünleri için önemli işlemlerden biri yıkama operasyonudur. Yıkama işlemi, dikilmiş denim giysinin, özel yıkama makinelerinde belirli reçete ve tekniklere göre yıkanarak üzerinde bulunan haşılların sökülmesi, değişik renk ve tuşe kazandırılması işlemidir. Jeans yıkama teknolojisi tüketici istekleri ve modanın etkisi ile yeni renk tonları ve efektler yaratma amacına yönelmiştir. Blue jeans'in temel özelliği, yıkandıkça rengi açılan indigo boyar madde ile boyanmış olmasıdır [3].
Yıkama oldukça zor ve deneyim gerektiren aşamalardan oluşur. $\mathrm{Bu}$ konuda yapılan araştırmalar ve deneyler sonrasında ortaya çıkan formüller, yıkanan kumaşlardan farklı renk ve etkiler elde edilmesini sağlamaktadır [4].

Zamanla kullanılmış görünümlü denim mamullere eğilimin artmasıyla, yıkama işletmelerinde kumaşlar, bir takım aşındırma işlemlerinden de geçirilmeye başlanmıştır. $\mathrm{Bu}$ amaçla, denim kumaştan üretilmiş mamullere, kumlama, zımparalama, lazer vb. gibi fiziksel; taş yıkama, enzim yıkama, taş yıkama, ağartma, vb. gibi kimyasal eskitme işlemleri uygulanabilmektedir [5].

\section{2. ÖNCEKİ ÇALIŞMALAR}

Literatürde denim yıkama işlemiyle ilgili çalışmalardan bazıları burada özetlenmiştir. Card ve arkadaşları [6], jean hazır giyim ürünlerinde yıkama işlemlerinin fiziksel özelliklere etkisini araştırmıştır. \%100 pamuk denim kumaştan hazırlanan jeanlere enzim ve taş yıkama işlemleri uygulanmış, yıkama öncesi ve yıkamalar sonrasındaki boncuklanma ve aşınma dayanımları incelenmiştir. Yıkama öncesi boncuklanma oranı enzim ve taş yıkamalardan fazla çıkmıştır. Aslan ve Körlü [5], yapılan çalışmada, haşıl sökme işlemi uygulanmış ve uygulanmamış çeşitli denim kumaş tipleri üzerinde farklı koşullarda uygulanan enzim ile yıkama işlemlerinin neden olduğu değişimler boyut, sıklık, renk ve ağırlık değişimleri, geri boyama, yırtılma dayanımı gibi parametreler açısından incelenmiştir. Deneysel çalışmaların sonucunda, denim kumaşlara enzimatik yıkama işlemi öncesinde haşıl sökme uygulanmasının söz konusu parametreler üzerinde etkili olduğu bulunmuştur. Khedher ve arkadaşları [7], endüstriyel bitim işlemlerinin denim kumaşların mekanik özellikleri üzerindeki etkilerini araştırmışlardır. 4 farklı yıkama (rins, enzim, taş, enzimli taş) ve 5 farklı özel uygulama (firçalama, zımpara, reçine, ağartma, permanganat sprey ile yumuşatma) üzerinden kombin çalışmalar yapılmıştır. Çalışmalar sonucunda, yıkama işlemlerinin kumaşın mekanik özelliklerini olumsuz etkilediği görülmüş istatistiksel olarak da 
aynı sonuç elde edilmiștir. Yi [8], çalıșmasında, enzim yıkama, enzimli ağartma, enzimli taş yıkama ve enzimli taş ve ağartma gibi yıkama proseslerinde, optimum y1kama efektinin yakalanması amacıyla, 1 ile 9 saat arası yıkama sürelerinde denemeler yapılmıştır. Çalışmada $\% 100$ pamuk ve \%99 pamuk \%1 elastan olmak üzere iki farklı kompozisyonda denim kumaş kullanılarak elde edilen numunelere yapilan yıkamaların kumaş kopma mukavemeti ve elastikiyet değerleri üzerine etkili olduğu görülmüştür. Khan ve arkadaşları [9], denim ürünlerde yapılan ağartma yıkamasında kullanılan ağartıcı miktarı, sıcaklık ve süre gibi parametrelerin kumaş kopma mukavemeti, katılık, elastikiyet, gramaj, renk kirletme, nem alma gibi özelliklerini ne yönde etkilediğini incelemiştir. Yapılan çalışmada, kopma mukavemeti, katılık, gramaj ve renk gibi parametrelerde azalma görülmüştür. Oğulata ve Nergis [10], yapılan çalışmada, yıkama koşullarının denim kumaş performansı üzerindeki etkisini araştırmak amacıyla, seçilmiş orta oz/yd $\mathrm{d}^{2}$ gramajlı bir denim kumaşa 4 farklı yıkama reçetesi baz alınarak, farklı koşullarda yıkamalar yapılmıştır. Çalışmada, denim yıkama endüstrisinde yoğun şekilde kullanılan bitim işlemlerinden, rins, enzim, taş ve taşlı ağartma yıkama reçetelerinde incelemeler yapılmıştır. Test sonuçlarının analizinde yıkama reçetelerinde uygulanan süre, sıcaklık ve kullanılan taş, enzim ve ağartıcı oranları bağımsız değişken, gramaj, en, yıkama sonrası boyutsal stabilite, dönme, çözgü uzama, katılık, kopma mukavemeti, yırtılma mukavemeti, elastikiyet ve kalıcı uzama değerleri ise bağımlı değişken olarak kullanılmıştır. Sonuçlara göre yıkamalarda genel olarak seçilen sıcaklık, enzim oranı, yıkama süresi, kimyasal oranı gibi parametrelerin hangilerinin ne oranda etkili olduğu konusunda çıkarımlar paylaşılmıştır. Nergis ve Oğulata [11], nötral bazlı enzimlerin denim kumaş özellikleri üzerine etkisini araştırmak amacıyla yapılan yıkamalarda farklı süre, sıcaklık ve enzim oranlarında denemeler yapılmıştır. Yapılan denemeler sonucunda ortaya çıkan sonuçların hangi parametrelerden ne ölçüde etkilendiği üzerinde durulmuştur. Nergis [12], rins yıkamanın, denim kumaş özellikleri üzerindeki etkilerini incelemiştir. Seçilen bir denim kumaşa, rins yıkama esnasında farklı sıcaklık ve süre seviyelerinde yıkama denemeleri yapılmıştır. Yapılan araştırmada, yıkamaların kumaşlar üzerindeki etkisini incelemek amacıyla, tekstil kumaşlarının performans tayininde kullanilan test metotları uygulanarak elde edilen sonuçlar istatistiksel metotlarla analiz edilmiştir. Deneysel çalışma sonuçlarının değerlendirilmesi ile; rins yıkama prosesinde yıkama süresinin gramaj, en, katılık, çözgü uzama, dönme, atkı kopma ve çözgü kopma sonuçları üzerinde etkili iken, sıcaklığın ise sadece atkı ve çözgü kopma mukavemet sonuçları üzerinde etkili olduğu görülmüştür. Çetinaslan ve arkadaşları [16], yaptıkları çalışmada, 3 farklı denim kumaş tipine uygulanan farklı yıkamalardan sonra, kopma ve yırtılma mukavemet testleri yapılmıştır. Elde edilen sonuçlarda kopma ve yırtılma mukavemetlerinde özellikle taş ve ağartma yıkamalarda mukavemet kayıplarının daha fazla olduğu, yumuşatıcı kullanılarak yapılan yıkamalarda yumuşatıcının yırtılma mukavemetini artırdığ 1 tespit edilmiştir.

\section{MATERYAL VE METOT}

\subsection{Materyal}

Yapılan yıkamalarda 7 farklı denim kumaş tipi kullanılmıştır. Kullanılan kumaşlara ait özellikler Çizelge 1'de sıralanarak 1'den 7'ye kadar kodlama yapılmıştır. Seçilen kumaşların genel denim kumaş üretimlerini temsil etmesi amaciyla, özellikle farklı elastikiyet düzeylerinde olmasına ve ince kalın gramajlardan örnekler içermesine dikkat edilmiştir. Seçilen 7 kumaş örneğine 6 farklı yıkama denemesi ve ham kumaş denemeleri yapılmış olup, bu yıkama işlemleri de göz önünde bulundurulduğunda toplamda 49 farklı yıkama numunesine denemeler yapılmıştır.

\subsection{Metot}

Yapılan çalışmada yıkamaların kumaş üzerinde etkisini görmek amacıyla kumaşlara yapılan yıkamalar sonrası mukavemet, elastikiyet ve kalıcı uzama testleri uygulanmıştır. Uygulanan testler ve metotlar Çizelge 2'de gösterilmiştir. 
Çizelge 1. Denemelerde kullanılan kumaş özellikleri

\begin{tabular}{|c|l|l|c|c|c|}
\hline Tip No & Çözgü İpliği & Atkı İpliği & Örgü & $\begin{array}{c}\text { Atkı } \\
\text { Sıklık }\end{array}$ & Çözgü Sıklık \\
\hline 1 & $\begin{array}{l}8,70 \mathrm{Ne} \text { Karde } \\
8,10 \mathrm{Ne} \text { Karde }\end{array}$ & $13,00 \mathrm{Ne}$ Karde + Elastan & $3 / 1 \mathrm{Z}$ & 19,5 & 30,5 \\
\hline 2 & $20,00 \mathrm{Ne}$ Karde & $24,00 \mathrm{Ne}$ Penye + Elastan + PBT & $3 / 1 \mathrm{Z}$ & 27 & 52 \\
\hline 3 & $13,50 \mathrm{Ne}$ Karde & $16,00 \mathrm{Ne}$ Karde + Elastan + PBT & $3 / 1 \mathrm{Z}$ & 22 & 43 \\
\hline 4 & $7,10 \mathrm{Ne}$ Karde & $10,00 \mathrm{Ne}$ Karde + Elastan & $3 / 1 \mathrm{Z}$ & 18,3 & 27 \\
\hline 5 & $8,10 \mathrm{Ne}$ Karde & $13,00 \mathrm{Ne}$ Karde + Elastan & $3 / 1 \mathrm{Z}$ & 19 & 28 \\
\hline 6 & $9,80 \mathrm{Ne}$ Karde & $\begin{array}{l}14,00 \mathrm{Ne} \text { Karde + Elastan } \\
13,00 \mathrm{Ne} \text { Karde + Elastan }\end{array}$ & $3 / 1 \mathrm{Z}$ & 20 & 31 \\
\hline 7 & $13,50 \mathrm{Ne}$ Karde & $20,40 \mathrm{Ne}$ Karde + Elastan + PES & $3 / 1 \mathrm{Z}$ & 25 & 44 \\
\hline
\end{tabular}

Çizelge 2. Denim kumaşlara uygulanan test metotlar1 ve kisaltmalar [13-15]

\begin{tabular}{|l|c|c|}
\hline \multicolumn{1}{|c|}{ Test Adı } & Birim & Test Metodu \\
\hline $\begin{array}{l}\text { Atkı Kopma } \\
\text { Mukavemeti [13] }\end{array}$ & $\mathrm{kg}$ & ASTM D 5034 \\
\hline $\begin{array}{l}\text { Çözgü Kopma } \\
\text { Mukavemeti [13] }\end{array}$ & $\mathrm{kg}$ & ASTM D 5034 \\
\hline $\begin{array}{l}\text { Atkı Yırtılma } \\
\text { Mukavemeti [14] }\end{array}$ & gr & ASTM D 1424 \\
\hline $\begin{array}{l}\text { Çözgü Yırtılma } \\
\text { Mukavemeti [14] }\end{array}$ & gr & ASTM D 1424 \\
\hline Elastikiyet [15] & $\%$ & ASTM D 3107 \\
\hline Kalıcı Uzama [15] & $\%$ & ASTM D 3107 \\
\hline
\end{tabular}

Yıkamalarda kullanılan reçeteler ve yıkama adımları Çizelge 3'de belirtilmiştir. Ev yıkaması electrolux wascator yıkama cihazında ISO 6330 1A yıkama programında, diğer yıkamalar ise endüstriyel yıkama makinesinde yapılmıştır. Enzim yıkamada nötral enzimler kullanılmıştır. Taş yıkamada da yıkama esnasında yine nötral enzimli yıkama yapılmıştır. Ağartma reçetesinde ise ağartma kimyasalı olarak hipoklorit kullanılmıştır. $\mathrm{Bu}$ reçeteler dışında kumaş yıkamasız ham halde de test edilerek yıkama sonrası elde edilen test sonuçlarıyla mukayese edilmiştir.

Çizelge 3. Kumaşlara uygulanan yıkama reçeteleri

\begin{tabular}{|c|c|c|c|}
\hline $\begin{array}{l}\text { Yıkama } \\
\text { Adı }\end{array}$ & Proses & $\begin{array}{c}\text { Zaman } \\
\text { (Dakika) }\end{array}$ & $\begin{array}{l}\text { Sicaklı } \\
\text { k }\left({ }^{\circ} \mathrm{C}\right)\end{array}$ \\
\hline $\begin{array}{l}\text { Ev } \\
\text { Y1kaması }\end{array}$ & $\begin{array}{l}\text { ISO } 63301 \mathrm{~A} \\
\text { Programı }\end{array}$ & 55 & 90 \\
\hline $\begin{array}{l}\text { Rins } \\
\text { Y1kama }\end{array}$ & Rins Y1kama & 5 & 30 \\
\hline \multirow{2}{*}{$\begin{array}{l}\text { Enzim } \\
\text { Y1kama }\end{array}$} & Haşıl Sökme & 14 & 60 \\
\hline & $\begin{array}{l}\text { Enzim } \\
\text { Y1kama }\end{array}$ & 25 & 60 \\
\hline \multirow{2}{*}{ Taş Yıkama } & Haşıl Sökme & 14 & 60 \\
\hline & Taş Yıkama & 50 & 60 \\
\hline \multirow{4}{*}{ A ğartma } & Haşıl Sökme & 14 & 60 \\
\hline & Taş Yıkama & 50 & 60 \\
\hline & Ağartma & 40 & 10 \\
\hline & Nötralizasyon & 30 & 10 \\
\hline
\end{tabular}

\section{BULGULAR VE TARTIŞMA}

Yapılan yıkama denemeleri sonrasında, kumaşlara atkı kopma, çözgü kopma, atk1 yırtılma, çözgü yırtılma, elastikiyet ve kalıcı uzama testleri uygulanmış olup, veriler istatistiksel metotlarla 
irdelenmiștir. Elde edilen sonuçlar Minitab istatistiksel analiz programı yardımıla değerlendirilmiştir.

\subsection{Kopma Mukavemeti Değerlendirilmesi}

7 farklı özellikte denim kumaşa yapılan yıkamalar ve elde edilen atkı ve çözgü yönündeki kopma mukavemeti test sonuçları Şekil 1 ve Şekil 2' de görülmektedir. $\mathrm{Bu}$ sonuçlara göre ağartma ve taş yıkama işlemlerinde, mukavemet sonuçlarının, diğer yıkama işlemlerine göre daha düşük geldiği görülmektedir. Kullanılan ponza taşıyla kumaşın fiziksel teması ve ağartmada kullanılan hipokloritin etkisiyle mukavemet kaybına uğrayan kumaşlarda, hem atkı hem de çözgü yönünde düşüşler yaşanmıştır.

Y1kama işleminin kopma mukavemeti üzerindeki etkileşimini görmek amacıyla varyans analizi uygulanmış olup sonuçlar Çizelge 4'de yer almaktadır. Önem derecesi 0,05 'e göre yapılan analize göre, yıkama işlemlerinin kopma mukavemeti üzerinde etkili olduğu görülmüştür. Hem çözgü yönünde hem de atkı yönünde değerlerin 0,05 'den düşük gelmesi neticesinde bu sonuçlara varılmaktadır.

Çizelge 4. Yıkama tipinin kopma mukavemeti üzerindeki etkisi

\begin{tabular}{|c|c|c|c|}
\hline Faktör & $\begin{array}{l}\text { Bağımlı } \\
\text { Değișken }\end{array}$ & $\mathbf{F}$ & Önemlilik \\
\hline \multirow{2}{*}{$\begin{array}{l}\text { Y1kama } \\
\text { Tipi }\end{array}$} & $\begin{array}{l}\text { Atk1 Kopma } \\
\text { Mukavemeti }\end{array}$ & 4,53 & 0,003 \\
\hline & $\begin{array}{c}\text { Çözgü } \\
\text { Kopma } \\
\text { Mukavemeti }\end{array}$ & 5,94 & 0,000 \\
\hline
\end{tabular}

Çizelge 5'de görülen Tukey metoduna göre yapılan çoklu karşılaştırma analizinde, çözgü yönünde kopma mukavemeti incelenmiştir. Çizelgedeki sonuçlara bakıldığında Taş yıkama ve ağartmalı yıkamanın diğer yıkamalarla arasındaki farkların anlamlı olduğu görülmüştür.
Çizelge 5. Çözgü kopma mukavemeti çoklu karşılaştırma sonuçları

\begin{tabular}{|c|c|c|c|c|}
\hline $\begin{array}{c}\text { Bağımlı } \\
\text { Değişken }\end{array}$ & $\begin{array}{c}\text { I } \\
\text { (Yıkama) }\end{array}$ & $\begin{array}{c}\mathbf{J} \\
\text { (Ylkama) }\end{array}$ & $\begin{array}{c}\text { Fark } \\
(\mathbf{I}-\mathrm{J})\end{array}$ & $\begin{array}{l}\text { Önem } \\
\text { Durumu }\end{array}$ \\
\hline \multirow{15}{*}{$\begin{array}{l}\text { Çözgü } \\
\text { Kopma }\end{array}$} & \multirow{5}{*}{ A ğartma } & Enzim & $-25,7$ & $0,005^{*}$ \\
\hline & & $\begin{array}{c}\text { Ev } \\
\text { Y1kamas1 }\end{array}$ & $-24,2$ & $0,010^{*}$ \\
\hline & & Ham & $-22,5$ & $0,020^{*}$ \\
\hline & & Rins & $-23,6$ & $0,013^{*}$ \\
\hline & & Taş & $-4,1$ & 0,988 \\
\hline & \multirow{4}{*}{ Enzim } & $\begin{array}{c}\text { Ev } \\
\text { Yikamas1 } \\
\end{array}$ & 1,4 & 1,000 \\
\hline & & Ham & 3,2 & 0,997 \\
\hline & & Rins & 2,1 & 1,000 \\
\hline & & Taş & $-21,5$ & $0,028^{*}$ \\
\hline & \multirow{3}{*}{$\begin{array}{c}\text { Ev } \\
\text { Yikamas1 }\end{array}$} & Ham & 1,7 & 1,000 \\
\hline & & Rins & 0,6 & 1,000 \\
\hline & & Taş & -20 & $0,049^{*}$ \\
\hline & \multirow{2}{*}{ Ham } & Rins & -1 & 1,000 \\
\hline & & Taş & $-18,3$ & 0,088 \\
\hline & Rins & Taş & $-19,4$ & 0,061 \\
\hline
\end{tabular}

Çizelge 6. Atkı kopma mukavemeti çoklu karşılaştırma sonuçları

\begin{tabular}{|c|c|c|c|c|}
\hline $\begin{array}{c}\text { Bağı̆ımlı } \\
\text { Değișken }\end{array}$ & I (Yıkama) & $\underset{\text { (Yıkama) }}{\mathbf{J}}$ & $\begin{array}{c}\text { Fark } \\
(\mathbf{I}-\mathbf{J})\end{array}$ & $\begin{array}{c}\text { Önem } \\
\text { Durumu }\end{array}$ \\
\hline \multirow{15}{*}{$\begin{array}{c}\text { Atk1 } \\
\text { Kopma }\end{array}$} & \multirow{5}{*}{ Ağartma } & Enzim & $-10,7$ & $0,016^{*}$ \\
\hline & & $\begin{array}{c}\text { Ev } \\
\text { Y1kamas1 } \\
\end{array}$ & $-9,5$ & $0,040^{*}$ \\
\hline & & Ham & $-8,5$ & 0,089 \\
\hline & & Rins & $-9,3$ & $0,048^{*}$ \\
\hline & & Taş & $-1,3$ & 0,998 \\
\hline & \multirow{4}{*}{ Enzim } & $\begin{array}{c}\text { Ev } \\
\text { Y1kaması }\end{array}$ & 1,1 & 0,999 \\
\hline & & Ham & 2,2 & 0,979 \\
\hline & & Rins & 1,3 & 0,998 \\
\hline & & Taş & 9,3 & $0,048^{*}$ \\
\hline & \multirow{3}{*}{$\begin{array}{c}\text { Ev } \\
\text { Y1kamasi }\end{array}$} & Ham & 1 & 0,999 \\
\hline & & Rins & 0,2 & 1,000 \\
\hline & & Taş & 8,2 & 0,108 \\
\hline & \multirow{2}{*}{ Ham } & Rins & $-0,8$ & 1,000 \\
\hline & & Taş & 7,1 & 0,214 \\
\hline & Rins & Taş & 7,9 & 0,126 \\
\hline
\end{tabular}




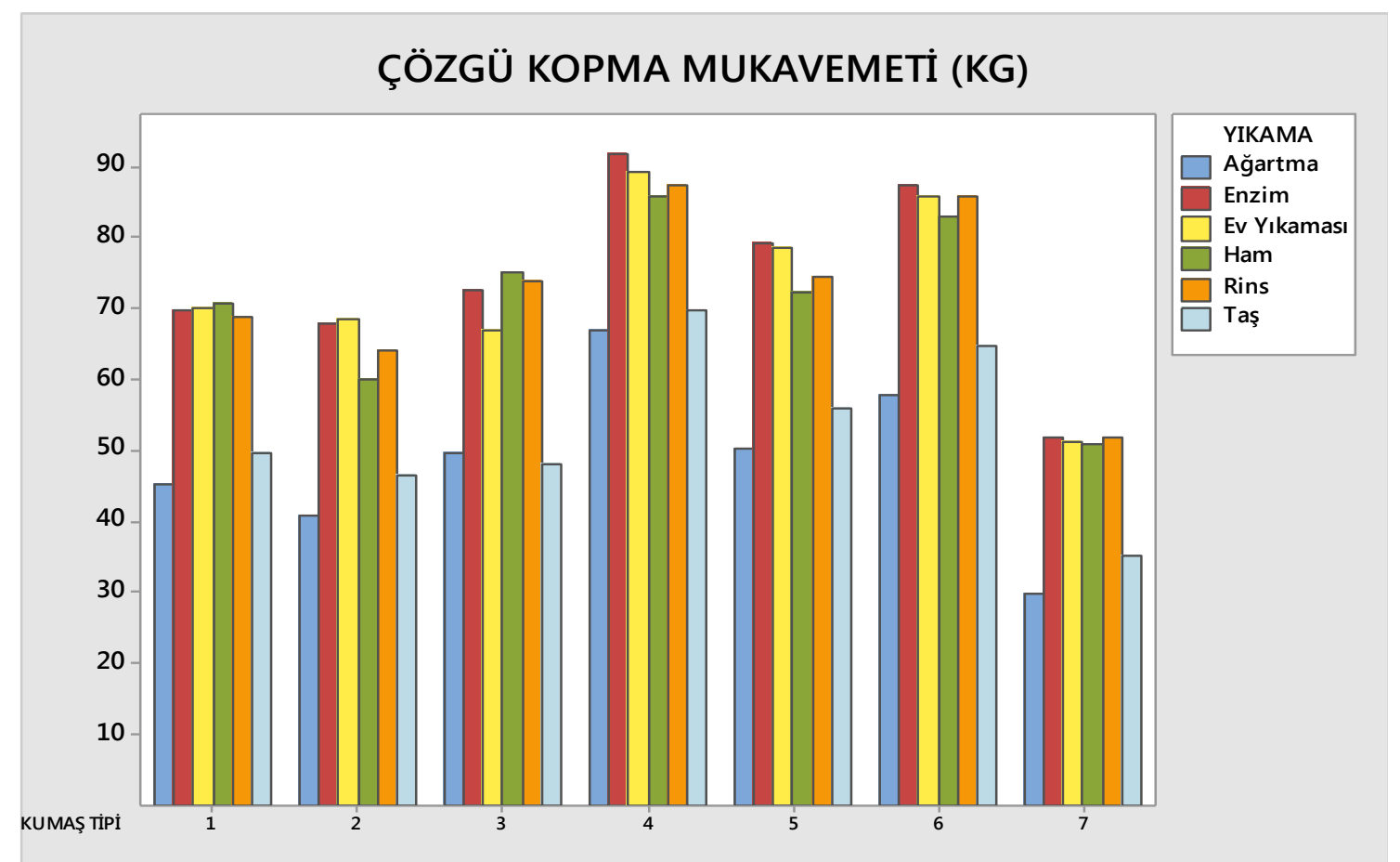

Şekil 1. Çözgü kopma mukavemeti test sonuçları

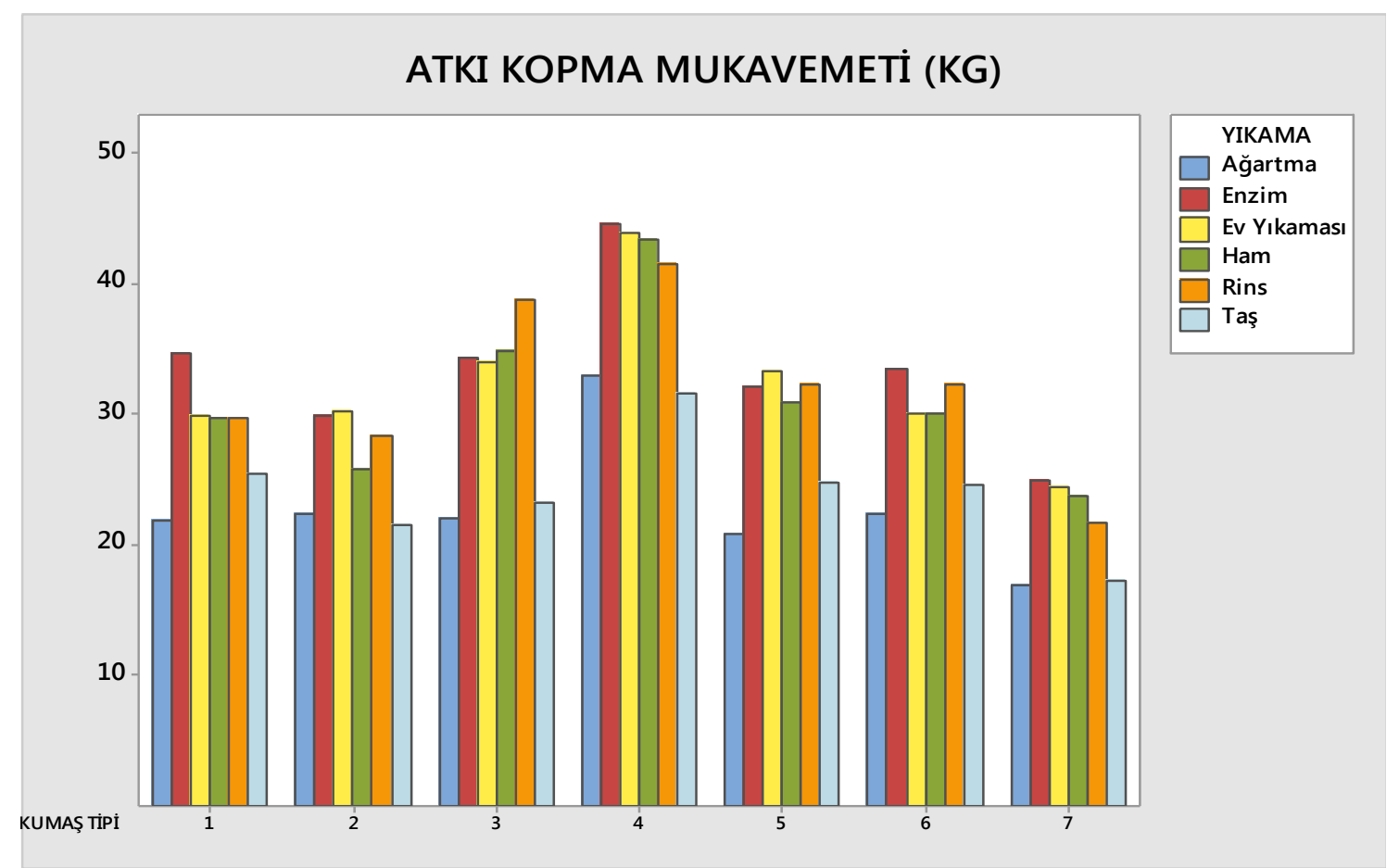

Şekil 2. Atk1 kopma mukavemeti test sonuçları 
Çizelge 6'daki atkı kopma çoklu karşılaştırma sonuçlarında da yine ham, enzim ve rins yıkama ile taş ve ağartma yıkamalar arasındaki farklar genel olarak anlamlı görülmektedir.

\subsection{Yırtılma Mukavemeti Değerlendirilmesi}

Şekil 3 ve Şekil 4'de gösterilen yıkamalar sonrası yırtılma mukavemeti sonuçlarında genel olarak kumaşın yıkamasız ham haline göre rins ve ev yıkamasında mukavemet sonuçlarının bir miktar yükseldiği görülmektedir. $\mathrm{Bu}$ durum kumaşın bu yıkamalar sonrası eninde ve boyundaki daralmalar sonucunda atkı ve çözgü sıklıklarının artması sonucu daha yoğun bir yapıya dönüşmesi sonucu ortaya çıkmıştır. Diğer yıkamalarda ise ham sonuçlara göre mukavemetlerde düşüş gözlenmektedir. Nötral enzim yıkamada atkı ve çözgü yönünde ortalamalara bakıldığında kısmi bir düşüş görülmekte olup, taş ve ağartma y1kamalarda mukavemet kaybı artmakta, kayıpların 1500-1800 gramlara çıktığı görülmektedir. Etkileşim sonuçlarına bakıldığında hem atkı hem de çözgü yırtılma mukavemetlerinde önemlilik değerlerinin 0,05 'den daha düşük gelmesi neticesinde yıkama tipinin bu değişkenler üzerinde etkili olduğu sonucu istatistiksel olarak ortaya çıkmaktadır. Çizelge 8 ve Çizelge 9'da görülen çoklu karşılaştırma sonuçlarına göre ortalamalar arasındaki en büyük farkların kopma mukavemetinde olduğu gibi taş ve ağartma yıkama ile diğerleri arasında olduğu görülmektedir. $\mathrm{Bu}$ tablolara göre çözgü yırtılma değişkeninde, ağartma yıkama ile ham rins sonuçları arasında, atk1 yırtılmada ise ağartma ile ev yıkaması arasında istatistiksel olarak anlamlı farklar tespit edilmiştir.

Çizelge 7. Yıkama tipinin yırtılma mukavemeti üzerindeki etkisi

\begin{tabular}{|c|c|c|c|}
\hline Faktör & $\begin{array}{c}\text { Bağımlı } \\
\text { Değişken }\end{array}$ & F & Önemlilik \\
\hline Y1kama & $\begin{array}{c}\text { Atk1 Yrrtılma } \\
\text { Mukavemeti }\end{array}$ & 3,04 & 0,022 \\
\cline { 2 - 4 } & $\begin{array}{c}\text { Çözgü } \\
\text { Yirtılma } \\
\text { Mukavemeti }\end{array}$ & 3,41 & 0,013 \\
\hline
\end{tabular}

Çizelge 8. Çözgü yırtılma mukavemeti yıkamalar arasındaki çoklu karşılaştırma sonuçları

\begin{tabular}{|c|c|c|c|c|}
\hline $\begin{array}{c}\text { Bağımılı } \\
\text { Değișken }\end{array}$ & $\begin{array}{c}\text { I } \\
\text { (Yıkama) }\end{array}$ & $\begin{array}{c}\mathbf{J} \\
\text { (Yıkama) }\end{array}$ & $\begin{array}{c}\text { Fark } \\
(\mathbf{I}-\mathbf{J})\end{array}$ & $\begin{array}{c}\text { Önem } \\
\text { Durumu }\end{array}$ \\
\hline \multirow{15}{*}{$\begin{array}{l}\text { Çözgü } \\
\text { Yırtılma }\end{array}$} & \multirow{5}{*}{ Ağartma } & Enzim & -1594 & 0,120 \\
\hline & & $\begin{array}{c}\text { Ev } \\
\text { Y1kaması }\end{array}$ & -1441 & 0,197 \\
\hline & & Ham & -1822 & $0,053^{*}$ \\
\hline & & Rins & -1853 & $0,047 *$ \\
\hline & & Taş & -361 & 0,991 \\
\hline & \multirow{4}{*}{ Enzim } & $\begin{array}{c}\text { Ev } \\
\text { Y1kaması }\end{array}$ & 153 & 1,000 \\
\hline & & Ham & -228 & 0,999 \\
\hline & & Rins & -259 & 0,998 \\
\hline & & Taş & 1233 & 0,350 \\
\hline & \multirow{3}{*}{$\begin{array}{c}\text { Ev } \\
\text { Yıkamas1 }\end{array}$} & Ham & -381 & 0,988 \\
\hline & & Rins & -412 & 0,984 \\
\hline & & Taş & 1080 & 0,496 \\
\hline & \multirow{2}{*}{ Ham } & Rins & -31 & 1,000 \\
\hline & & Taş & 1461 & 0,185 \\
\hline & Rins & Taş & 1493 & 0,168 \\
\hline
\end{tabular}

Çizelge 9. Atkı yırtılma mukavemeti yıkamalar arasındaki çoklu karşılaştırma sonuçları

\begin{tabular}{|c|c|c|c|c|}
\hline $\begin{array}{l}\text { Bağımlı } \\
\text { Değișken }\end{array}$ & $\begin{array}{c}\text { I } \\
\text { (Yıkama) }\end{array}$ & $\begin{array}{c}\mathbf{J} \\
\text { (Yıkama) }\end{array}$ & $\begin{array}{l}\text { Fark } \\
\text { (I-J) }\end{array}$ & $\begin{array}{c}\text { Önem } \\
\text { Durumu }\end{array}$ \\
\hline \multirow{15}{*}{$\begin{array}{c}\text { Atk1 } \\
\text { Yirtılma }\end{array}$} & \multirow{5}{*}{ Ağartma } & Enzim & -805 & 0,457 \\
\hline & & $\begin{array}{c}\text { Ev } \\
\text { Y1kamas1 }\end{array}$ & -1410 & $0,031^{*}$ \\
\hline & & Ham & -1047 & 0,188 \\
\hline & & Rins & -1124 & 0,133 \\
\hline & & Taş & -263 & 0,990 \\
\hline & \multirow{4}{*}{ Enzim } & $\begin{array}{c}\text { Ev } \\
\text { Y1kamasi }\end{array}$ & -604 & 0,740 \\
\hline & & Ham & -241 & 0,994 \\
\hline & & Rins & -319 & 0,977 \\
\hline & & Taş & 542 & 0,816 \\
\hline & \multirow{3}{*}{$\begin{array}{c}\text { Ev } \\
\text { Y1kamas1 }\end{array}$} & Ham & 363 & 0,960 \\
\hline & & Rins & 286 & 0,986 \\
\hline & & Taş & 1147 & 0,120 \\
\hline & \multirow{2}{*}{ Ham } & Rins & -77 & 1,000 \\
\hline & & Taş & 784 & 0,487 \\
\hline & Rins & Taş & 861 & 0,383 \\
\hline
\end{tabular}




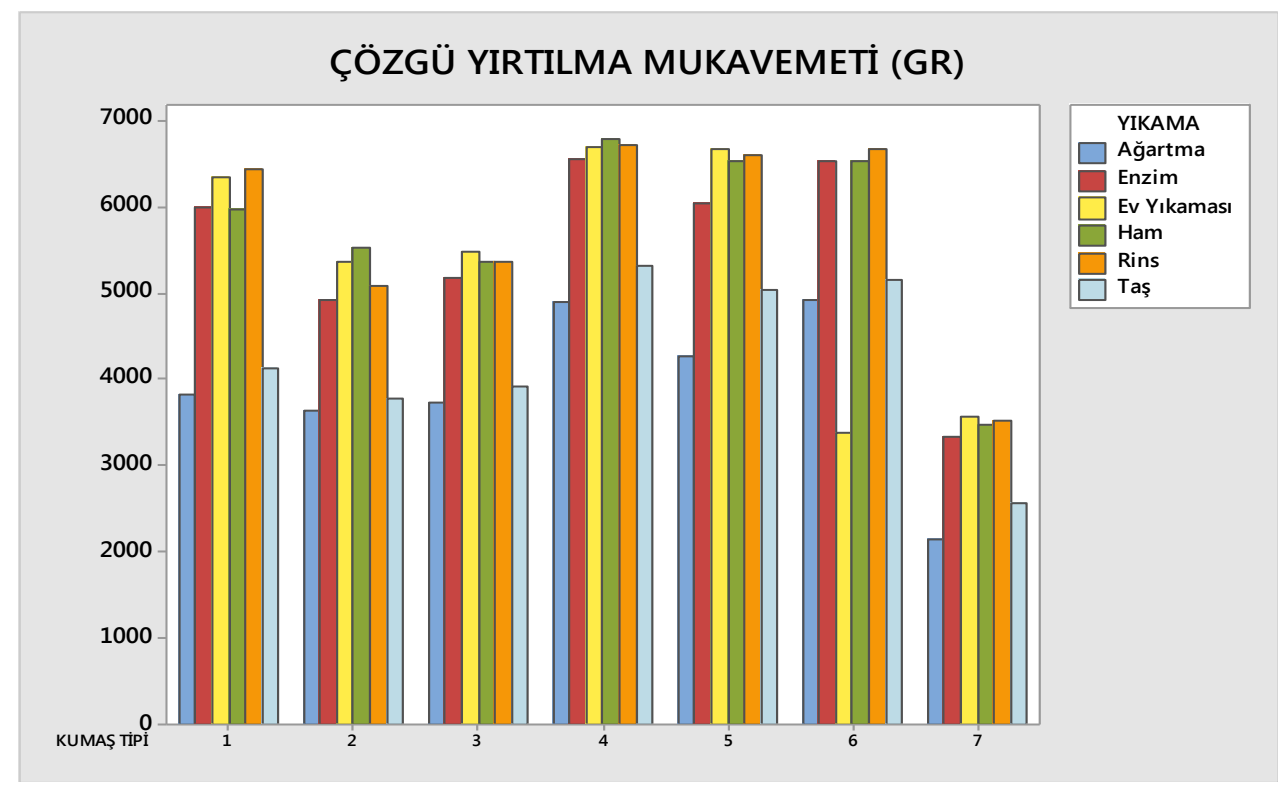

Şekil 3. Çözgü yırtılma mukavemeti test sonuçları

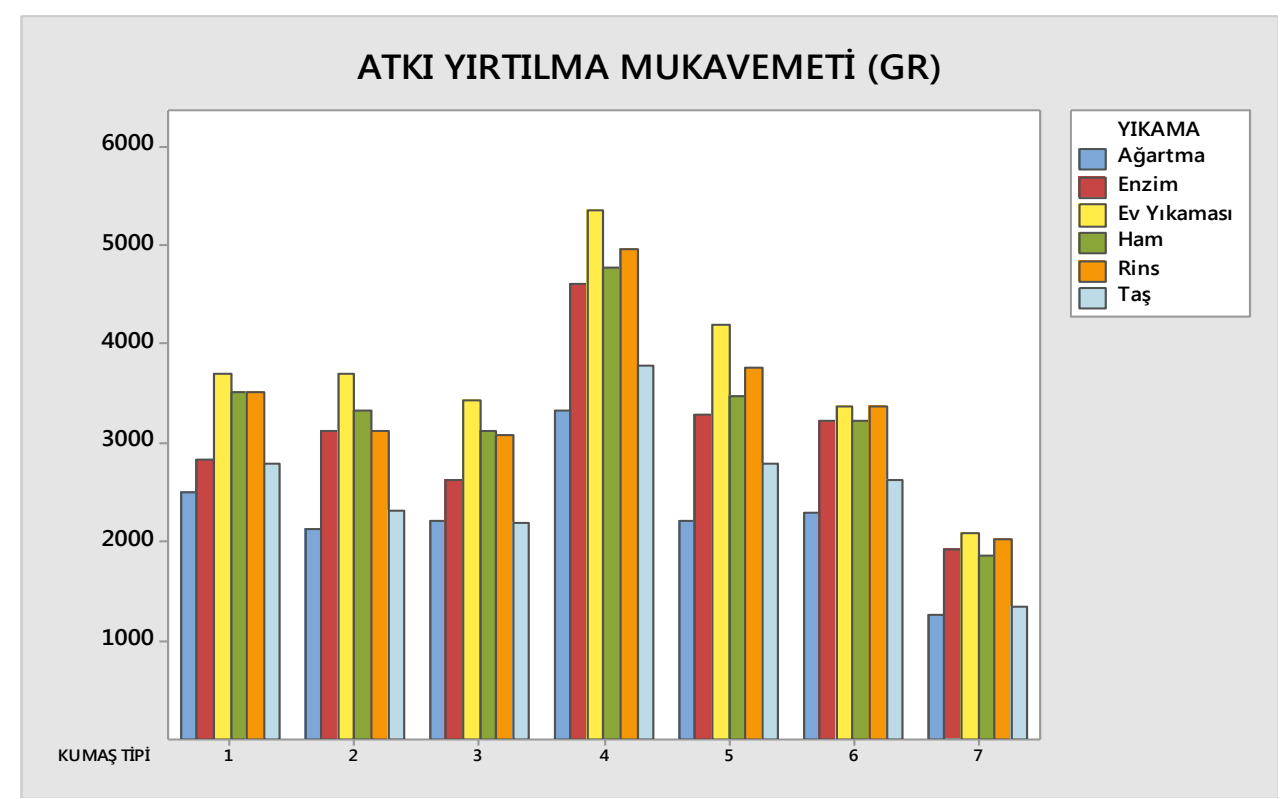

Şekil 4. Atkı yırtılma mukavemeti test sonuçları

\subsection{Elastikiyet ve Kalıcı Uzama Sonuçlarının Değerlendirilmesi}

Şekil 5'de bulunan elastikiyet sonuçları incelendiğinde genel olarak yıkamalı sonuçlarda değerlerin birbirine yakın seyrettiği görülmektedir.
Ham sonuçlarda kumaşın atkı yönünde eni geniş olduğundan ve birim alandaki iplik sıklıklarının seyrek olmasından ve aralardaki boşlukların fazla olmasından dolayı esneme payı düşüktür. Yıkama sonrası ise kumaş enine daraldığından esneme imkanı daha fazla olacaktır. Ağartmalı yıkamada 
elastanın ağartıcıdan etkilenmesiyle esneme yani elastikiyet miktarı diğer yıkamalara göre bir miktar düşük gelse de sonuçlar arasında büyük farklar bulunmamaktadır. Şekil 6'daki kalıcı uzama sonuçlarına bakıldığında ise ham kumaşta esneme fazla olmadığından kalıcı uzamanın da düşük geldiği görülmektedir. Rins yıkamada yıkama süresinin ve sıcaklığın düşük olması nedeniyle kalıcı uzamanın diğer yıkamalara göre düşük geldiği, ev yıkaması, enzim, taş ve ağartma yıkamalarda ise kalıcı uzama sonuçlarının daha yüksek seyrettiği görülmüştür.

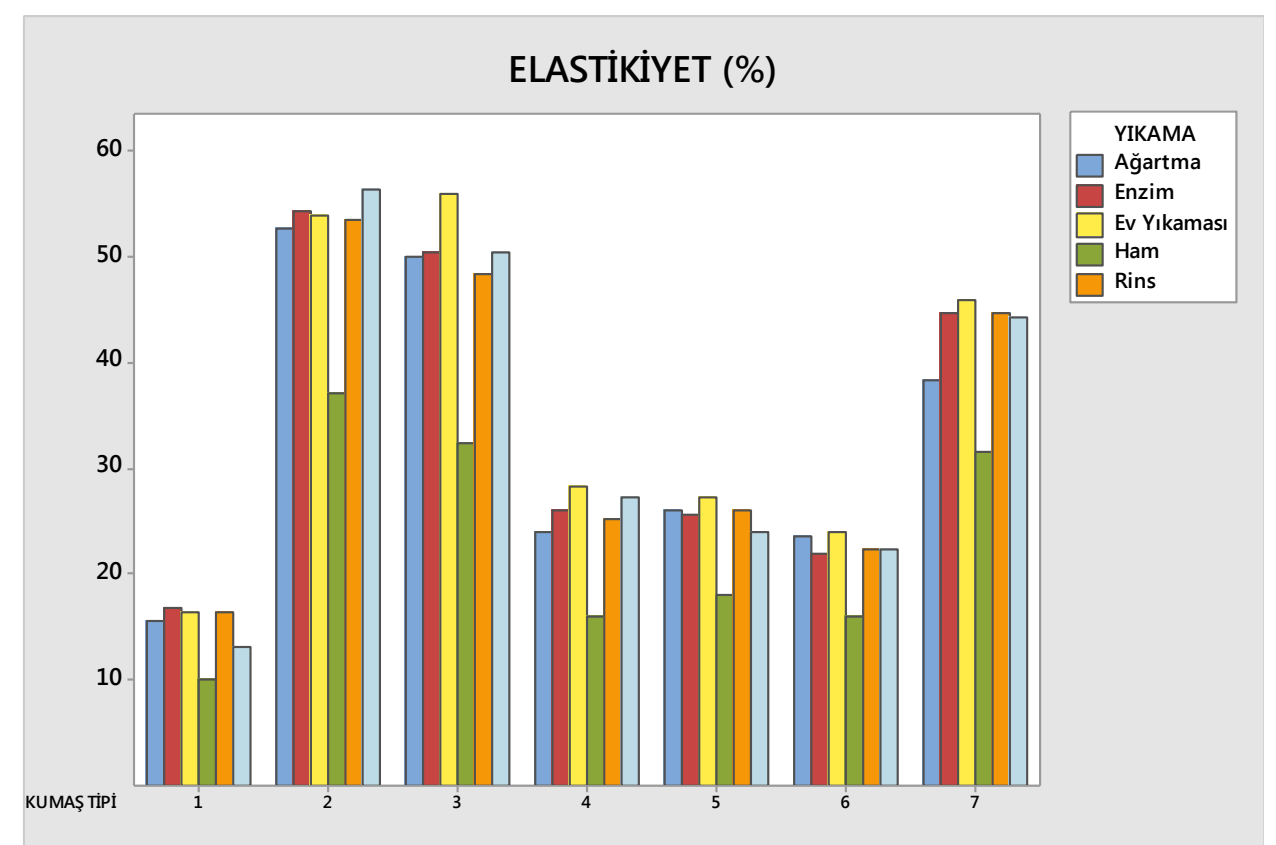

Şekil 5. Elastikiyet test sonuçları

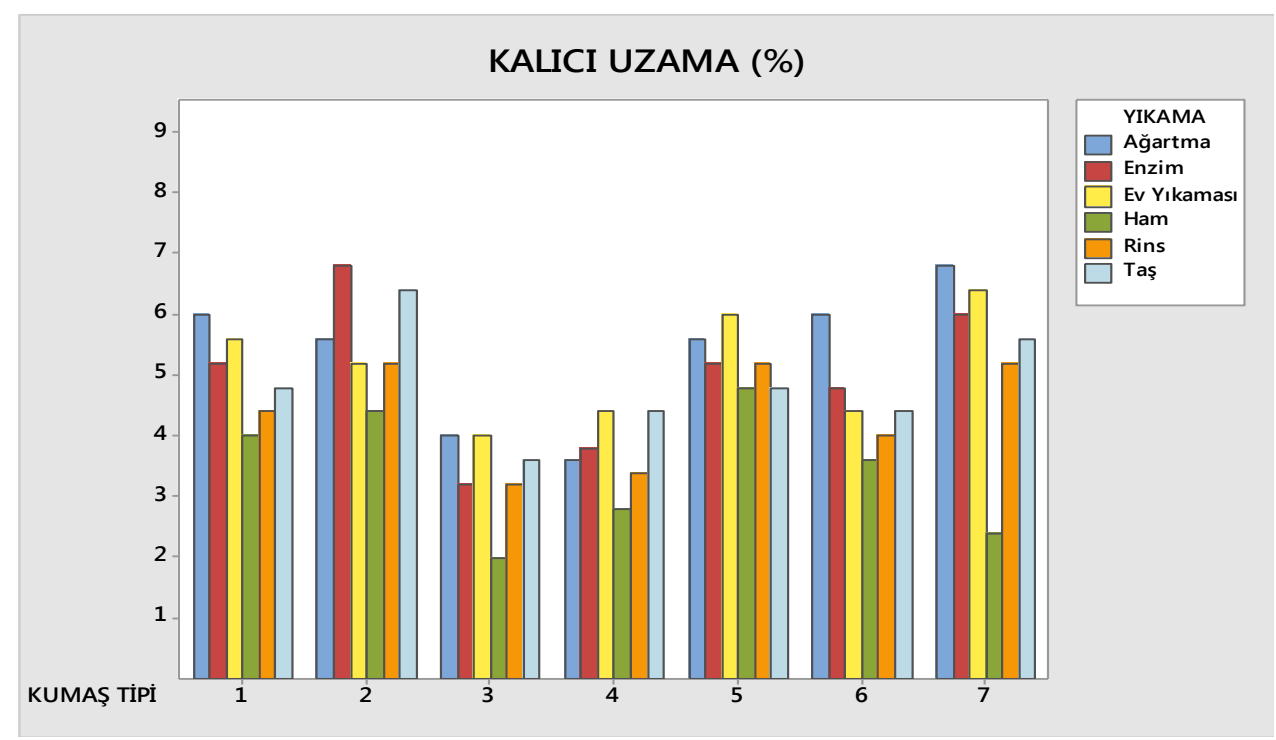

Şekil 6. Kalıcı uzama test sonuçlar 
Çizelge 10. Yıkama tipinin elastikiyet ve kalıcı uzama üzerindeki etkisi

\begin{tabular}{|c|c|c|c|}
\hline Faktör & $\begin{array}{c}\text { Bağımlı } \\
\text { Değişken }\end{array}$ & $\mathbf{F}$ & Önemlilik \\
\hline $\begin{array}{c}\text { Yıkama } \\
\text { Tipi }\end{array}$ & $\begin{array}{c}\text { Kastikiyet } \\
\text { Ualıma }\end{array}$ & 0,72 & 0,612 \\
\hline
\end{tabular}

Çizelge 10 'da bulunan varyans analizinde elastikiyet değişkeninde önemlilik değerinin 0,05 'den büyük ve hipoteze göre yıkama ortalamaları arasında hiç birinin farklı olmadığı, yani elastikiyet üzerinde yıkama tipinin etkisinin olmadığı sonucu ortaya çıkmaktadır. Kalıcı uzama sonuçlarında ise önemlilik değeri 0,05 'den düşük olması nedeniyle yıkama tipinin kalıcı uzama üzerinde etkili olduğu tespit edilmiştir.

Çizelge 11. Kalıcı uzamanda yıkamalar arasındaki çoklu karşılaştırma sonuçları

\begin{tabular}{|c|c|c|c|c|}
\hline $\begin{array}{c}\text { Bağımlı } \\
\text { Değişken }\end{array}$ & $\begin{array}{c}\text { I } \\
\text { (Yıkama) }\end{array}$ & $\begin{array}{c}\mathbf{J} \\
\text { (Yıkama) }\end{array}$ & $\begin{array}{c}\text { Fark } \\
(\mathbf{I}-J)\end{array}$ & $\begin{array}{c}\text { Önem } \\
\text { Durumu }\end{array}$ \\
\hline \multirow{15}{*}{$\begin{array}{l}\text { Kalıcı } \\
\text { Uzama }\end{array}$} & \multirow{5}{*}{ Ağartma } & Enzim & 0,68 & 0,984 \\
\hline & & $\begin{array}{c}\text { Ev } \\
\text { Yıkaması }\end{array}$ & 0,42 & 0,998 \\
\hline & & Ham & 3,54 & $0,013^{*}$ \\
\hline & & Rins & 1,82 & 0,467 \\
\hline & & Taş & 0,94 & 0,934 \\
\hline & \multirow{4}{*}{ Enzim } & $\begin{array}{c}\text { Ev } \\
\text { Y1kamas1 }\end{array}$ & $-0,26$ & 1,000 \\
\hline & & Ham & 2,86 & 0,071 \\
\hline & & Rins & 1,14 & 0,860 \\
\hline & & Taş & 0,26 & 1,000 \\
\hline & \multirow{3}{*}{$\begin{array}{c}\text { Ev } \\
\text { Y1kaması }\end{array}$} & Ham & 3,12 & $0,038^{*}$ \\
\hline & & Rins & 1,4 & 0,725 \\
\hline & & Taş & 0,52 & 0,995 \\
\hline & \multirow{2}{*}{ Ham } & Rins & $-1,72$ & 0,531 \\
\hline & & Taş & $-2,6$ & 0,124 \\
\hline & Rins & Taş & $-0,88$ & 0,948 \\
\hline
\end{tabular}

Çizelge 11'deki kalıcı uzama için yapılan çoklu karşılaştırma sonuçlarına göre, ham kumaşla, ağartma ve ev yıkaması ortalamaları arasındaki farkın anlamlı olduğu görülmektedir. Esnemenin fazla olmaması nedeniyle ham kumaşın çok fazla uzamadığı, bu nedenle elastik bölgeden fazla uzaklaşmayarak kalıcı deformasyonun düşük olduğu görülmektedir. Yıkamalı kumaşlarda ise esnemenin fazla olması nedeniyle bütün yıkamalarda ham kumaşa göre kalıcı uzamanın fazla olduğu görülmektedir.

\section{SONUÇLAR}

Kopma mukavemet sonuçlarına göre hem atkı hem de çözgü yönünde yıkamalara göre değerlerdeki değişimin birbirine yakın olduğu görülmüsstür. Yıkama sonrası özellikle taş ve ağartma yıkamalarda mukavemetin her iki yönde de zayıfladığı tespit edilmektedir. Literatürde yer alan çalışmalarda da kopma mukavemetiyle ilgili benzer sonuçlara ulaşıldığ 1 görülmektedir. Khedher [7], Yi [8], Khan [9] ve Nergis [10], tarafindan yapılan çalışmalarda, taş yıkama ve ağartmalı yıkamalarda mukavemetlerdeki zayıflamanın fazla olduğu tespit edilmiştir. $\mathrm{Bu}$ yıkamalarda elde edilen sonuçların kopma mukavemeti üzerinde istatistiksel olarak anlamlı ve etkili olduğu ortaya koyulmuştur.

Ham kumaşta atk1 ve çözgü yönünde değerlerin genelde enzim, rins ve ev yıkamasına göre yakın fakat bir miktar daha düşük olduğu, nedeninin ise bu yıkamalardan sonra atkı ve çözgü yönündeki daralmalardan dolayı, iplik sıklıklarının artması ve daha mukavim hale geldiği görülmüştür. Taş ve ağartma yıkamada ise hem taştan kaynaklı fiziksel temasın hem de ağartıcıdan kaynaklanan kimyasal yıpranmanın kumaş mukavemetini düşürdüğü görülmüştür.

Yırtılma mukavemetinde, yıkama tipinin sonuçlar üzerinde istatistiksel olarak anlamlı değişimlere neden olduğu tespit edilmiştir. Çetinaslan ve arkadaşları [16] tarafından yapılan çalışmada, taş yıkama ve ağartıcı kullanılarak yapılan yıkamalar sonrasında, elde edilen yırtılma mukaveti sonuçlarının, yıkamasız kumaşlarda ve rins yıkama sonrasında elde edilen sonuçlara göre çok daha düşük değerlerde olduğu tespit edilmiştir. Yırtılma mukavemetinde en düşük sonuçlar ağartmalı yıkamada elde edilmiştir. Taş yıkamada ise sonuçların ağartmaya göre bir miktar daha yüksek fakat diğer yıkamalardan ve ham değerlerden düşük olduğu görülmüştür. Ev yıkaması, enzim yıkama, rins yıkama ve ham kumaş testlerinin değerlerinin birbirine yakın olduğu, bu yıkamaların arasında en düşük ortalamaların ev yıkamasında 
gerçekleştiği tespit edilmiştir. Ev yıkamasında elde edilen değerlerin düşük gelmesiyle ilgili olarak, yıkama sıcaklığının $90^{\circ} \mathrm{C}$ ve yıkama süresinin 55 dakika olması nedeniyle diğer yıkamalardan daha uzun ve yüksek sicaklıkta gerçekleşmesinin yırtılma mukavetini düşürmesinden kaynaklandığı görülmektedir.

Yapılan testler sonucunda elastikiyet test sonuçları üzerinde yıkama tipinin anlamlı bir etkisi görülmemiştir. Y1kamaya göre elde edilen test ortalamalarının birbirine yakın gelmesi nedeniyle varyans analizlerinde elastikiyetle ilgili anlamlı bir etkileşim görülmemiştir. Elde edilen sonuçlara göre elastikiyet değerlerinin ham kumaşta yıkanmış kumaşlara göre çok düşük olduğu, yıkama sonrası enine daralmadan dolayı yıkamanın esnemeyi artırdığı görülmüştür. Kalıcı uzama değerlerine bakıldığında ise, elde edilen değerlerin yıkama tipiyle etkileşiminin istatistiksel olarak anlamlı olduğu sonucuna varılmıştır. Esnemenin düşük olması nedeniyle kalıcı uzamanın da düşük olduğu görülmüş olup, ham kumaşlarda test sonuçları en alt seviyede kaldığı tespit edilmiştir. Yıkamalara bakıldığında ise yıkama süresinin kısa olması nedeniyle en düşük kalıcı uzama değerinin rins yıkamada meydana geldiği görülmüştür. Diğer yıkamalarda ise kalıcı uzama değerlerinin yükselme eğiliminde olduğu tespit edilmiştir.

\section{KAYNAKLAR}

1. Bağıran, İ.C., 2011. Denim Yikamada Karşılaşılan Sorunlar ve Bunlara Yönelik Çözüm Önerileri, Ege Üniversitesi Fen Bilimleri Enstitüsü Tekstil Mühendisliği, Yüksek Lisans Tezi, İzmir.

2. Karal, Ö., Denim Kumaşlarda Yıkamanın Dikiş ve Kumaş Üzerindeki Etkisi, Yüksek Lisans Tezi, İstanbul Teknik Üniversitesi, Fen Bilimleri Enstitüsü, Tekstil Mühendisliği Ana Bilim Dalı, İstanbul, 1996.

3. Dindar, D., Yavuz, B., 2001. 2000-2001 Moda Trendleri ve Kot Pantolon-Mont Üretimi, Marmara Üniversitesi Teknik Eğitim Fakültesi Tekstil Eğitimi Bölümü, Yüksek Lisans Tezi, İstanbul.
4. Megep, 2006. Giyim Üretim Teknolojisi Kadın Jean Pantolon Kalıbı, Ankara.

5. Aslan, M., Korlu, A., 2009. Selülaz Enziminin Denim Yikamada Kullanımı. Tekstil Teknolojileri Elektronik Dergisi, 3(1):11-23.

6. Card, A., Moore, M.A., Ankeny, M., 2006. Garment Washed Jeans: Impact of Launderings on Physical Properties, International Journal of Clothing Science and Technology, Vol.18, No:2, 43-52.

7. Khedher, F., Dhouıb, S., Msahlı, S., Saklı, F., 2009. The Influence of Industrial Finishing Treatments And Their Succession on The Mechanical Properties of Denim Garment, Autex Research Journal, Vol.9, No:3. 93-100.

8. Yi, C.M., 2011. Effect Of Washing on Tensile Strength of Denım Fabri, A Thesis Degree of Bachelor of Arts (Honours) Scheme in Institute of Textiles \& Clothing, The Hong Kong Polytechnic University. Hong Kong.

9. Khan M.R., 2011. Effect of Bleach Wash on The Physical And Mechanical Properties of Denım Garments, International Conference on Mechanical Engineering, 87-93, Dhaka, Bangladesh.

10. Nergis, A., Oğulata R.T., 2016. Rins Yıkamanın Denim Kumaş Performansı Üzerindeki Etkilerinin Araştırılması, Çukurova Üniversitesi Mühendislik Mimarlık Fakültesi Dergisi, Vol.31, No.2, 421-435.

11. Nergis, A., Oğulata R.T., Mezarcıöz S.M., 2016. Nötral Selülaz Enzim Yıkamanın Denim Kumaş Performansı Üzerindeki Etkilerinin Araştırılması, International Mediterranean Science and Engineering Congress, Adana.

12. Nergis, A., 2016. Denim Kumaşlarda Farklı Yıkama Proseslerinin Kumaş Performans Özelliklerine Etkisi, Çukurova Üniversitesi, Fen Bilimleri Enstitüsü, Tekstil Mühendisliği Anabilimdalı, Yüksek Lisans Tezi.

13. ASTM D5034-9, 2013. Standard Test Method for Breaking Strength and Elongation of Textile Fabrics (Grab Test), ASTM International.

14. ASTM D1424-09, 2013. Standard Test Method for Tearing Strength of Fabrics by FallingPendulum (Elmendorf-Type) Apparatus, ASTM International. 
Farklı Yıkamaların Denim Kumaş Performansı Üzerindeki Etkilerinin Araştırılması

15. ASTM D3107-07, 2015. Standard Test Methods for Stretch Properties of Fabrics Woven from Stretch Yarns, ASTM International.

16. Çetinaslan K., Mezarcıöz S., Çetiner S., 2013. Yıkama İşleminin Denim Kumaşların Kopma ve Yirtılma Mukavemetine Etkisi, KSU Mühendislik Bilimleri Dergisi, Vol.31, No.1, $38-42$. 